\title{
TEN RULES FOR DEALING WITH NEGATIVE CONTRIBUTIONS IN SOCIAL MEDIA
}

\author{
Stránská, A., Stříteský, V.
}

\begin{abstract}
Social media is becoming a key part of business communication strategy. Despite all the advantages, social media also poses a threat to business reputation. Dissatisfied customers can reach a large audience and share their negative experiences with others. This paper deals with the impact of social media on the practice of public relations. The goal of the paper is to formulate a set of rules for dealing with negative contributions and generally with crisis communication in social media. It is based on two surveys. Individual interviews with social media experts are the core part of the analysis. They are complemented by questioning of consumers to get deeper insight into complaining behavior via social media. The defined set of rules provides a useful tool for the social media crisis management.
\end{abstract}

Keywords: crisis communication; social media; online reputation; Facebook JEL classification: M31

\section{Introduction}

Marketers see the presence of social media as an interesting opportunity. A message can now be delivered easier; the reach is significant, the budget lower than with traditional media. Consumers can be kept informed and engaged. However, all the benefits have corresponding drawbacks on the other side and social media can be a double edged sword. Not only is information spread within the network at tremendous speed, it is also an amplifier. Word of mouth, nowadays the most powerful marketing tool and the strongest argument in the decision making process, is not limited to the circle of nearest friends and family any longer. For instance, the average (mean) number of friends among adult Facebook users is 338 and the median comes in at 200 friends (Smith, 2014). Before social media, an unsatisfied customer had only limited means to deliver his complaint. $\mathrm{He} / \mathrm{she}$ could conduct a one-on-one battle with the company via letter, phone calls or e-mail and tell his friends about his outrage. Social media gives people a voice that is immediate and can have impact (Chavez, 2011). Without an effective and fast reaction of the company, serious harm can be suffered. Social media can also influence the level of impact category. A complaint of a single customer, once regarded as a crisis with minimal impact, can grow very quickly within the social media and become a situation that has to be resolved as soon as possible.

The purpose of this paper is to define a set of recommendations for successful communication in social media, when dealing with negative customer contributions or even with a crisis situation. It is focused particularly on the biggest social network platform Facebook. 


\section{Crisis Communication}

Crises are part of doing business. Being prepared to communicate during a crisis is a part of business too (Van der Hurk, 2013). As Finks states, "there are few guarantees in business today. Unfortunately, one of them is the inevitability of a crisis having a potentially major effect on your business and your reputation" (Fink, 2013). Being a part of business means that crisis management is something that should be already there, not something a company starts to elaborate once a crisis occurs. A basic definition of crisis management is a "set of activities, performed toward preventing and evaluating of events of various origins without initiating prevention steps, but trying to diminish the chances of risk development, or by initiating protective steps, trying to reduce the risk effects" (Regester and Larkin, 2008). The term "crisis management" could be very simply defined as "special measures taken to solve a problem caused by a crisis" (Devlin, 2006). A crisis communication should not be mixed with is a quick-fix or universal solution that is applied whenever an uneasy situation occurs (Darling, Seristö and Gabrielsson, 2005).

\section{Figure 1 | Crises typology matrix}

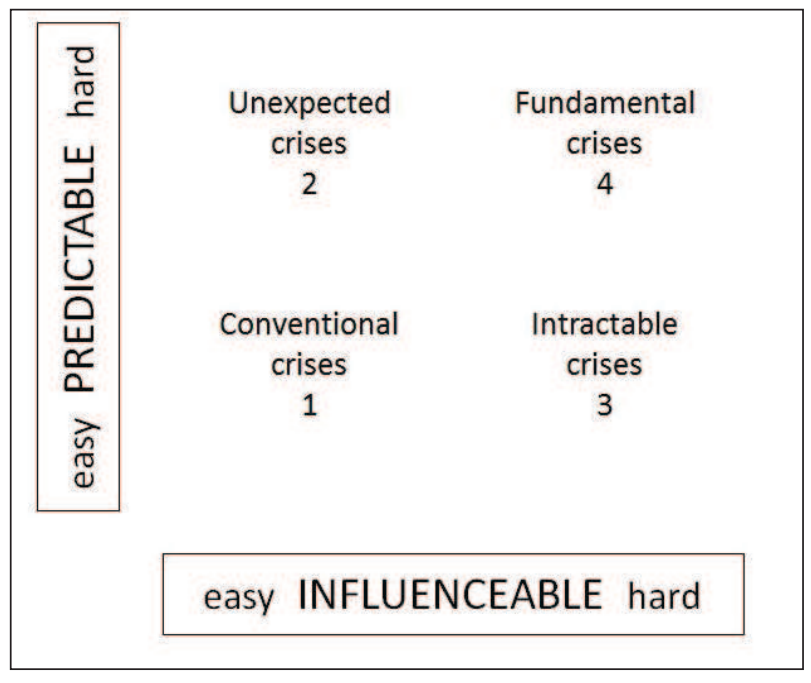

Source: (Gundel, 2005)

According to Gundel (2005), crises are classified according to how predictable (high vs. low) and influenceable (high vs. low) they are (see Figure 1). This generates four types of crises: Conventional, Unexpected, Intractable and Fundamental. Although Gundel admits that "classifying crises is like shooting a moving target", because future events are likely to be very different from those of today, and today's unforeseen events may in retrospective no longer be seen as a crisis. 
Most authors (e.g. Devlin, 2006; McDonald and Crawford, 2012; Malone and Coombs, 2009; Lando, 2014) distinguish between three basis stages of a crisis:

1. pre-crisis stage,

2. acute crisis stage,

3. post crisis stage.

In the pre-crisis stage, it is crucial to define notification and monitoring systems. Within a company, there should be a dedicated person or team who will be prepared to take the actions from the crisis response plan. Once the crisis moves from the first stage to the acute one, it becomes visible outside the organization. The main steps within this stage are mainly gathering all information available and informing about the issues that affected stakeholders. If a problem occurs, it is perceived better when the company informs the interested parties rather than them finding out via the media or elsewhere. Once a crisis is over, the central question becomes: What are the learnings? Did our crisis response plan worked according to our expectations? What was good and where is there still some improvement potential? Only satisfied customers will recommend a company to other people and make repeated purchases (Tahal, 2014).

\section{Crisis Communication in Social Media}

A large number of companies are understandably hesitant to enter social media. Many of them have spent decades on developing branding guidelines and messaging requirements. Historically, only those with media and PR training were allowed to make public statements (Fox, 2010). However, even if they preserve their conservative approach, they cannot control the branding message any more. People are talking about them online already. Insisting on not being present on social media can become very risky when a crisis occurs. This idea is also supported by the PR Daily World Conference, where the principle "give up control to get control" was named among the main five PR and social media trends for 2014 (Lawlor, 2013). According to Lochridge (2011), it is important to address the crisis initially in the same channel where it arose. That is the only way to gain control. If it's a YouTube video, the company should respond with a YouTube video as well.

The emergence of social media has changed the rules to a large extent. Nowadays, every crisis finds its way into the social media, either by accident or purpose, but always with consequences (Capozz and Rucci, 2013). The information users get via social media is regarded as very trustworthy. This fact shouldn't be underestimated by any company and negative information about their business should be taken seriously. Blogs and social media have made communications more instantaneous by encouraging organizations to respond more quickly to criticism (Write and Hinson, 2008). Publications on crisis management, which were released before social media started mixing the cards, often talk about the so-called "Golden 24 hours". In the age of social media, hours turn into minutes.

Gundel's model (2005) from the previous section is easy to apply in the case of social media as well. What changes in the environment of social networks is the distribution within the categories. Considering the predictability dimension, a large amount of critical issues moved from the quadrant "predictable" to the quadrant "unpredictable". The reason is mainly the open and viral character of social media. The prediction is also complicated by crossing all geographical and cultural boundaries. Posting a statement 
which might be considered insensitive by a group on the other side of the world can cause serious harm.

A further reason which contributes to the lower predictability is the incompetence of marketers or PR specialists to understand what is allowed and not within the social media networks (Malshe, 2008). Only very big companies have a designated person or team that is specialized on social media exclusively. There are many companies which are still handling their marketing and PR activities in the traditional way. However, they hear and read that buzzwords such as "social", "Facebook" or "tweet" are spelled all the time and create their own account, feeling to have done all that is necessary. These companies are often very surprised when a crisis occurs.

A crisis can occur outside of social media and social media can be seen as a tool to mitigate the crisis. The next level of handling a crisis is the usage of social media proactively. According to a PWC survey (2013), companies are recently re-thinking their approach to crisis management. However, the majority of them (57\%) are still behind in leveraging social media as the main source.

\section{Methods}

To assess the current situation in the Czech Republic in terms of crisis communication in social media, two surveys were conducted. A sample of twenty professionals was asked to take part in expert interviews. The aim was to cover both employees of digital and social media agencies and employees responsible for social media in corporations. Twelve of them agreed to participate and discuss the topic. Each interview lasted about one hour. By sharing their experience, the following types of questions were examined:

1. How do they react to contributions with a negative sentiment?

2. What do they see as the biggest failures of social media admins?

3. What are the basic rules for handling a crisis?

4. What are the best precautionary measures for not letting a crisis escalate?

To see the problem from an additional point of view, a special interview was held with a psychologist to discuss questions such as:

1. What is the hidden motivation of people who complain publicly over social media?

2. What are practical tips for social media admins from a psychological perspective?

Besides the expert interviews, a supplementary questionnaire survey of consumers was conducted to answer following core questions:

1. When unsatisfied with a product or service, how likely is it that a person will complain via social media?

2. What is the motivation behind complaining via social media?

3. How fast do complainers expect to get a solution?

4. Are they satisfied with the suggested solution and what do they see as the biggest failures of social media admins?

The sample size was 200 respondents. Quota sampling and snowball sampling were used. The sample reflects the gender and age structure of the Czech Internet population. As for 
other characteristics, the sample is not fully representative. The questionnaire consisted of 17 questions divided into two parts. One set of questions was aimed at respondents that complain via social media, another one at those that prefer other channels. For the purpose of this paper, only the key findings from the questionnaire survey are presented. Most of the defined rules are based on a literature review and findings from expert interviews.

\section{Key Findings from Questionnaire Survey}

As for the consumer survey, results have shown that every fifth unsatisfied customer complains on the respective corporate Facebook page (see Figure 2). The main advantage of using this channel is seen as the speed of making the issue public. With the current high penetration of smartphones, social media users are instantly online. Writing a short message on a Facebook wall takes only a few moments.

\section{Figure 2 | Preferred channels for complaints}

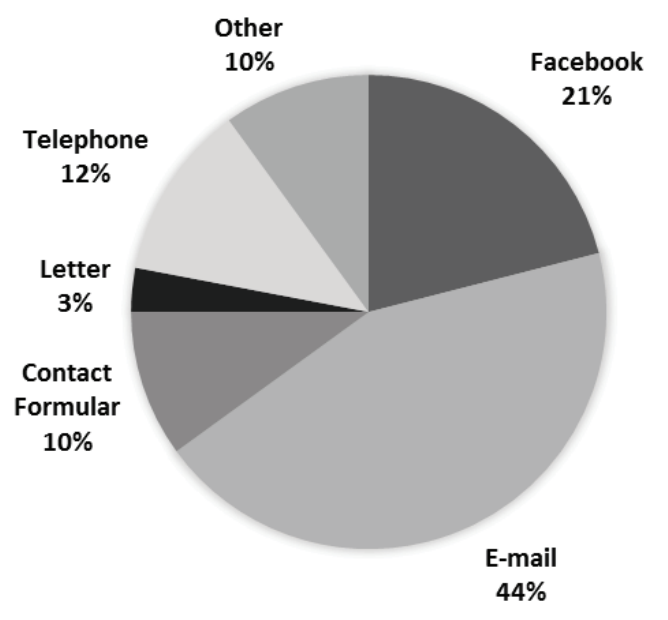

Source: authors, $\mathrm{N}=200$

Social media users also expect a reply significantly quicker. One third of respondents expect a company's reaction within an hour. Over half are willing to wait one day and only 10 percent two days or longer. This demand is already known to most companies. It was not a surprise that phone, as a channel, scored very poorly. In the comments, few respondents mentioned that they used to choose phone, but calling an 800 number has become "a nightmare" in the case of big companies. Complainers also rely on fact that when making it public, companies will try to 'save face' and be more generous in the proposed reimbursement.

Negative customer contributions in social media may cause serious problems. On-line reviews and recommendations of other customers are a very trustworthy source of information for a purchase decision. Most respondents $(74.7 \%)$ stated that they get references on the Internet (blogs, social media) to avoid bad experiences with the product or service.

If a negative contribution is posted on company's social media page, sometimes 
failures of the administrator lead to escalation of the problem. The admin responding with a pre-prepared phrase $(52.4 \%)$ is perceived as the biggest mistake. This technique is a common part of a customer service helpdesk, but via social media, customers expect something more. Ignoring a complaint is perceived as number two in the ranking $(35.7 \%)$, followed closely by deleting the complaint from the wall completely (33.3\%).

Interestingly, people who complain via traditional media are more satisfied with the suggested compensation than people who complain via social media. The average value is 2.65 , compared with 2.86 in the case of social media. The question was directed to the average satisfaction of the suggested reimbursement on the scale from 1 (= very satisfactory) to 5 (=unsatisfactory).

\section{Key Findings from Expert Interviews}

Experts agree that a good knowledge of the community is a core condition for choosing the right tone of voice. Running a page is easier when the admin himself is part of the community, or a part of the customer target group. If not, it is good to sit down with someone from this community to exchange some insights. This is sometimes very challenging for freelancers or people working in an agency, who often run several pages simultaneously and have to keep a consistent tone of voice on every page.

As proposed strategies how to react the most complaints via social media were mentioned, e.g., a patient explanation; admitting a mistake when necessary (especially in the case of big corporations, admitting a failure often serves as an icebreaker that leads to a friendly tone); showing an understanding and involvement (empathy) - this applies to cases when a social media admin has no power at all to change the situation or offer the complainer some kind of reimbursement; fast reaction; forwarding a contact (phone, mail) if the customer wants some thorough explanation; showing alternatives (complaints about a product -- recommendation of another one from the portfolio).

To have some comparable data with the outcomes of the questionnaire, the panelists were asked the same questions as the respondents form the survey. Specifically, these were: "What do you see as a biggest failure of social media admins in crisis communication" and "What is an adequate response time?" Whereas questionnaire respondents consider as the biggest failure "answering with an obvious predefined question", according to the professionals it is deleting the messages. Based on their experience, deleting a complaint led, in most cases, to escalation of the issue. When there is really no other option but to delete the contribution (the content is insulting, vulgar etc.), it is practical advice to inform the user in advance and explain why it has to be removed.

In the case of acceptable response time, the professionals are stricter with themselves than what the users expect. Half of them think that a reaction to a post should come within the first hour, whereas only one third of the social media users expect the reply so quickly. One of the professionals mentioned a golden rule $1 / 24$ hours. This means that in many cases, the admin is not able to answer a question or suggest a solution to a complaint in the desired time. Especially in the case of agencies or freelancers who have to contact a person within a company first and try to find a proper answer together. In these cases, the rule is easy to apply. Within the first hour, the company lets the user know that they have received the complaint and have started the process of dealing with it. When keeping the second part of the rule, a solution is suggested within 24 hours. 
To get more insights about the crisis management, the experts were asked to formulate one basic rule for dealing with negative contributions. The mentioned rules were as follows:

- "Keep calm and think of the clients."

- "Our customer, our boss."/ "Customer first."

- "Do your best to understand the customer and his/her problem."

- "Take criticism as valuable feedback."

- "Has my reply contributed to solving the customer's trouble?"

- “Openness and authenticity. “

- "Answer in the shortest time possible".

- "No matter what, stay nice."

- "What does the complainer really want?"

- "Avoid computer speech, stay human".

- "Do not let yourself be blackmailed by the fans".

Based on the special interview with the psychologist, three types of customer complaints were defined. An admin should be able to categorize a complainer in one of the complaint-types.

As for a factual complaint without excessive emotions, it is crucial to send a quick signal that a company is acknowledging the complaint and ready to negotiate a solution. Once a reimbursement is agreed, the probability of spreading further negative word of mouth is very limited. Moreover, if the complainer is pleased with the compensation, he becomes more loyal than a customer without any trouble with the particular product or service.

A general complaint full of emotions and insults is the second type. These people often use the safe zone of the Internet and social media to harm somebody or vent some anger. The crucial step of the admin is to drag him/her from this comfort zone. A recommended reaction would be "Dear XYZ, Customer feedback is very valuable for us. If you have some concrete issues in mind, please leave us your contact information, so that our representative can give you a call and discuss the situation with you. Thank you."

The third type is a complaint where no concrete solution is needed. From the experience of the interviewed PR experts and the psychologist, people often complain about something over the Internet, but the true reason for their dissatisfaction lies somewhere else. Instead of an effort to find some solution, it is more efficient to provide them with some comfort. This comfort can have the form of showing understanding, admitting that they are right, appreciating their constructive feedback and ideas.

\section{Conclusion and Managerial Implications}

Based on the synthesis of findings from both the literature review and the surveys, 10 key rules for dealing with negative contributions and crisis communication in social media were defined. They are structured according to the importance before, during and after a critical event. 


\section{Pre-crisis / Crisis prevention}

1. Listening, monitoring and exploiting the analytics.

Every social media platform has a unique community. Therefore, as experts mentioned, without insights from these particular groups, the communication will never be efficient. The focus should not be concentrated exclusively on the particular page, but rather on all connections with the brand. Usage of specialized software is recommended (ex. Ataxo Social Insider, eMerite, etc.). The better a social media administrator knows the audience, the better communication he/she can deliver.

\section{Definition the influencers.}

Social media has changed the pattern companies use to communicate with the broad public. One of the shifts is that the discussion should move from the question "how many will get the message" to "to whom should we deliver the message". Based on the results of the questionnaire survey, people trust online recommendations and reviews $(74.7 \%$ get information on the Internet to avoid bad experiences). It is crucial for companies to identify the biggest influencers and create for them a special position in the communication strategy.

\section{Social media should become a part of the CRM system.}

Information provided by the customer helpdesk and by the social media admin should be consistent (Freher, 2014; Pang, Nasrath Begam and Chong, 2014; Owyang, 2011). In many companies, the helpdesk and administration of the social media are done by two different departments. It is important to ensure that both those channels are providing the same information. This results in a more consistent brand experience for customers. A challenge that big corporation are dealing with nowadays is how to match customers that contact the company by various channels - e-mail, telephone and social media platforms. Ideally, measuring the influence of people in social media should be reflected in CRM activities. Some companies go even further. A company in Egypt is measuring the influence of people in social media. The biggest influencers are automatically gaining a higher priority in the system (Brejlová, 2014). As Owyang (2011) states, companies of all social business maturity levels currently suffer from the inability to integrate social data into existing technology systems.

\section{Only professionals should be hired.}

There are still companies that are hiring students or low-qualified workers to be in charge of hotlines and social media, e.g. Facebook. An example of this mentioned by one of the experts in the interview is the corporate Facebook page of Hera, a popular baking margarine. The content was prepared by a student who searched for recipes online (mainly cooking and food blogs) and used them on the Hera page, without any authorization from the author. After several bloggers stood up, the company had to issue an apology.

\section{Definition of all possible weak spots.}

A very good knowledge not only of the company's products and services, but also of all the processes helps the effective communication. By identifying all possible sources of customer complaints, the need time for dealing with them shortens and the risk of escalation decreases. A strategic decision has to be made, whether to outsource the social media 
communication or do everything in-house. In the case of hiring a freelancer or agency, the company should be ready to share a big amount of information, including very sensitive data.

\section{Acute crisis}

\section{Structured scenarios do not work anymore.}

Companies used to prepare structured scripts to deal with different types of crises. As shown in the questionnaire survey, people hate getting pre-defined answers. Since all contributions in social media are visible for everybody, a more or less unique response has to be created for various critical events. The necessity of preparing plans is still unchanged, but in a more flexible way. Most PR specialists recommend communicating in a less corporate tone.

\section{Admins should not let themselves be bullied by the complainers.}

This recommendation was mentioned by experts as one of the basic rules for dealing with negative contributions. It is part of human nature that everyone wants to find out where the border is. The rule "the customer is always right" has to be respected, but every company has its own profitability borders and values they stand for, which should not be crossed. Setting the rules from the beginning is often very well accepted. Anything that is out of these boundaries shouldn't be promised.

\section{Negative feedback does not necessarily mean bad things.}

This statement is true for various reasons. First of all, what people search for is authenticity. To a certain extent, a few negative comments add trustworthiness to the positive content published by a company and other fans. Secondly, a significant value can be taken from constructive feedback. What used to be gained through expensive surveys and focus groups is now presented on social media for free. Thirdly, there is always a chance to turn anger into loyalty. With social media, we can quicken the whole complaint process, which significantly shortens the time when an angry customer is spreading negative sentiments via word of mouth. Both surveys have shown that erasing complaints is one of the worst mistakes a crisis manager can do. Unless the content is extraordinarily rude, insulting minorities etc., no contribution should be deleted. In most cases, this leads only to worsening of the situation.

\section{Decipher what complainers really want and how to help them.}

This rule is based on the findings from expert interviews and the special interview with the psychologist. Finding out what a person who is complaining really wants can be trickier than one could think and requires a big portion of empathy. Sometimes at least a basic knowledge of psychology is needed to resolve a critical situation. People hang out on social media when they are bored; because of this, brand new terms have been adopted into language, such as "trolls". In these cases, the basic techniques of assertiveness should be used. 


\section{Post - crisis}

\section{Evaluation of all steps in the crisis communication.}

One of the advantages of social media is instant feedback. As experts mentioned, also criticism is valuable feedback. By regular evaluation of past steps, valuable experience is gained. Those who stop improving cease to be good.

\section{References}

Brejlová, I. (2014). Krizová komunikace na sociálních sítích: jak zvládnout průser (accessed February 7, 2015), [available at http://www.tyinternety.cz/socialni-site/ krizova-komunikace-na-socialnich-sitich-jak-zvladnout-pruser/].

Capozzi, L., Rucci S. R. (2013). Crisis management in the Age of Social Media, Business Expert Press, LLC,

Chavez, G. (2011). Social media can help-or hinder-crisis communication efforts. Communication World, 28 (6): 38.

Darling, J., Saristö, H., Gabrielsson, M. (2005). Anatomy of Crisis Management: A Case Focusing on a Major Cross-cultural Clash within DaimlerChrysler; (accessed February 2, 2015), [available at http://Ita.hse.fi/2005/3/ Ita_2005_03_a1.pdf].

Devlin, E. S. (2006). Crisis management planning and execution. Boca Raton: Auerbach Publications, Taylor and Francis Group.

Fink, S. (2013). Crisis Communication, The definite guide to managing the message. New York: McGraw Hill Education.

Fox, V. (2010). Marketing in the age of Google. Hoboken: John Wiley \& Sons Inc.

Freher, S. (2014). Social media and the world of work: A strategic approach to employees' participation in social media. Corporate Communications, 19 (4): 344-356.

Gundel, S. (2005). Towards a new typology of crises. Journal of Contingencies and Crisis Management, 13 (3): 106-115.

Lando, A. L. (2014). The critical role of crisis communication plan in corporations' crises preparedness and management. Global Media Journal, 7 (1): 5-19.

Lawlor, J. (2013). 5 PR and social media trends for 2014, (accessed February 7, 2015), [available at http://www.prdaily.com/Main/Articles/5_PR_and_social_media_ trends_for_2014_15667.aspx\#].

Lochridge, L. (2011). Dealing with A social media crisis. Florida Grower, 104 (12): 34.

Malone, P. C., Coombs, W. T. (2009). Introduction to Special Issue on Crisis Communication. Journal Of Public Relations Research, 21 (2): 121-122.

Malshe, A. (2008). A Typology of Social Media Crises, (accessed February 7 , 2015), [available at https://www.academia.edu/attachments/11533045/ download_file?st=MTQxNjU4NDI1OCw2Mi4xNTkuMjQxLjEyNSwyMTkwNDc4Mg\%3D\%3D\&s=swp-toolbar]. 
McDonald, J., Crawford, I. (2012). Inter-organisational post-crisis communication. Corporate Communications, 17 (2): 173-186.

Owyang, J. (2011). Social business readiness: how advanced companies prepare internally. (accessed February 22, 2015), [available at http://www.slideshare.net/ jeremiah_owyang/social-readiness-how-advanced-companies-prepare].

Pang, A., Nasrath Begam, A. H., \& Chong, A. C. Y. (2014). Negotiating crisis in the social media environment: Evolution of crises online, gaining credibility offline. Corporate Communications, 19 (1): 96-118.

PwC survey: Many businesses still wary about utilizing social media as a crisis management tool. (2013). Professional Services Close - Up, (accessed February 8, 2015), [available at https://search.proquest.com/ docview/1425358318?accountid=17203].

Regester, M., \& Larkin, J. (2008). Risk issues and crisis management in public relations: A casebook of best practice. London: Kogan Page.

Smith, A; 6 new facts about Facebook, 2014, Pewresearch.org, available on http:// www.pewresearch.org/fact-tank/2014/02/03/6-new-facts-about-facebook/.

Tahal, R. (2014). Výzkum spokojenosti zákazníků. Marketing \& komunikace. 24 (4): 13-14.

Van den Hurk, A.M. (2013). Social Media Crisis Communications, Pearson Education Inc.

Wright, D. K., \& Hinson, M. D. (2008). How blogs and social media are changing public relations and the way it is practiced. Public relations journal, 2 (2): 1-21.

\section{Authors}

\section{Ing. Adriana Stránská}

Faculty of Business Administration

Department of Marketing

University of Economics, Prague

W. Churchill Sq. 4, 13067 Prague, Czech Republic

xstra06@vse.cz

\section{Ing. Václav Stříteský, Ph.D.}

Faculty of Business Administration

Department of Marketing

University of Economics, Prague

W. Churchill Sq. 4, 13067 Prague, Czech Republic

vaclav.stritesky@vse.cz 